\title{
Sex, gender, and retinoblastoma: analysis of 4351 patients from 153 countries
}

Ido Didi Fabian ${ }^{1,2}{ }^{\circledR}$, Vikas Khetan ${ }^{3}$, Andrew W. Stacey ${ }^{4}$, Allen Foster ${ }^{1}$, Dupe S. Ademola-Popoola ${ }^{5}$, Jesse L. Berry ${ }^{6}$, Nathalie Cassoux ${ }^{7}$, Guillermo L. Chantada ${ }^{8}{ }^{8}$, Laila Hessissen ${ }^{9}$, Swathi Kaliki ${ }^{10}{ }^{10}$, Tero T. Kivelä ${ }^{11}{ }^{11}$, Sandra Luna-Fineman ${ }^{12}$, Francis L. Munier ${ }^{13}$, M. Ashwin Reddy ${ }^{14,15}$, Duangnate Rojanaporn ${ }^{16}$, Sharon Blum ${ }^{2}$, Sadik T. Sherief ${ }^{17}$, Sandra E. Staffieri (iD ${ }^{18}$, Tuyisabe Theophile ${ }^{19}$, Keith Waddell $^{20}$, Xunda $\mathrm{Ji}^{21}$, Nicholas J. Astbury ${ }^{1}$, Covadonga Bascaran (iD ${ }^{1}$, Matthew Burton ${ }^{1}$, Marcia Zondervan ${ }^{1}$, Richard Bowman (D ${ }^{1,22}$ \& On behalf of the Global Retinoblastoma Study Group

(c) The Author(s) 2021

OBJECTIVE: To investigate in a large global sample of patients with retinoblastoma whether sex predilection exists for this childhood eye cancer.

METHODS: A cross-sectional analysis including 4351 treatment-naive retinoblastoma patients from 153 countries who presented to 278 treatment centers across the world in 2017. The sex ratio (male/female) in the sample was compared to the sex ratio at birth by means of a two-sided proportions test at global level, country economic grouping, continent, and for selected countries.

RESULTS: For the entire sample, the mean retinoblastoma sex ratio, 1.20, was higher than the weighted global sex ratio at birth, $1.07(p<0.001)$. Analysis at economic grouping, continent, and country-level demonstrated differences in the sex ratio in the sample compared to the ratio at birth in lower-middle-income countries $(n=1940), 1.23$ vs. $1.07(p=0.019)$; Asia $(n=2276)$, 1.28 vs. $1.06(p<0.001)$; and India $(n=558), 1.52$ vs. $1.11(p=0.008)$. Sensitivity analysis, excluding data from India, showed that differences remained significant for the remaining sample $\left(x^{2}=6.925\right.$, corrected $\left.p=0.025\right)$ and for Asia $\left(x^{2}=5.084\right.$, corrected $p=$ 0.036). Excluding data from Asia, differences for the remaining sample were nonsignificant $\left(x^{2}=2.205, p=0.14\right)$.

CONCLUSIONS: No proof of sex predilection in retinoblastoma was found in the present study, which is estimated to include over half of new retinoblastoma patients worldwide in 2017. A high male to female ratio in Asian countries, India in specific, which may have had an impact on global-level analysis, is likely due to gender discrimination in access to care in these countries, rather than a biological difference between sexes.

Eye (2022) 36:1571-1577; https://doi.org/10.1038/s41433-021-01675-y

\section{INTRODUCTION}

Sex has long been recognized as an important factor influencing cancer risk, incidence, response to treatment and prognosis, including in children $[1,2]$. In retinoblastoma, the most common intraocular malignancy in children [3], sex-related differences, and specifically the sex ratio, have not been thoroughly investigated. This may be attributed to the fact that retinoblastoma is a rare disease, hence reported study cohorts are relatively too small to demonstrate any real difference between the sexes. Additionally, the mutated gene in almost all retinoblastoma cases, $R B 1$, is assigned to chromosome 13 [4], with only few reports describing a link to sex chromosomes [5-7].

In most clinical studies on retinoblastoma in which the sex ratio was recorded, no valid statistical analysis was undertaken to determine whether a significant difference between sexes existed. Furthermore, despite the fact that retinoblastoma is a childhood cancer, most studies did not take into account the sex ratio at birth, which across the world is $>1$ in favor of males [8]. In the few studies that did, results were mixed, showing male [9-11], female [12], or no preponderance at all $[13,14]$. Only a single study based on

\footnotetext{
${ }^{1}$ International Centre for Eye Helath, London School of Hygiene \& Tropical Medicine, London, UK. ${ }^{2}$ The Goldschleger Eye Institute, Sheba Medical Center, Tel Hashomer, Tel-Aviv University, Tel-Aviv, Israel. ${ }^{3}$ Sankara Nethralaya, Chennai, India. ${ }^{4}$ Department of Ophthalmology, University of Washington, Seattle, WA, USA. ${ }^{5}$ University of Ilorin Teaching Hospital, University of Ilorin, Ilorin, Kwara State, Nigeria. ${ }^{6}$ Children's Hospital Los Angeles, Keck School of Medicine, University of Southern California, Los Angeles, CA, USA. ${ }^{7}$ Institut Curie, Université de Paris Medicine Paris V Descartes, Paris, France. ${ }^{8}$ Hospital Sant Joan de Déu, Barcelona, Spain. ${ }^{9}$ Pediatric Hematology and Oncology Department of Rabat, Mohammed V University, Rabat, Morocco. ${ }^{10}$ The Operation Eyesight Universal Institute for Eye Cancer, L V Prasad Eye Institute, Hyderabad, India. ${ }^{11}$ Ocular Oncology Service, Department of Ophthalmology, Helsinki University Hospital, University of Helsinki, Helsinki, Finland. ${ }^{12}$ Hematology/Oncology/SCT, Center for Global Health, Children's Hospital Colorado, University of Colorado, Aurora, CO, USA. ${ }^{13}$ Jules-Gonin Eye Hospital, Fondation Asile de Aveugles, University of Lausanne, Lausanne, Switzerland. ${ }^{14}$ The Royal London Hospital, Barts Health NHS Trust, London, UK. ${ }^{15}$ Moorfields Eye Hospital NHS Foundation Trust, London, UK. ${ }^{16}$ Department of Ophthalmology, Faculty of Medicine, Ramathibodi Hospital, Mahidol University, Bangkok, Thailand. ${ }^{17}$ Department of Ophthalmology, School of Medicine, Addis Ababa University, Addis Ababa, Ethiopia. ${ }^{18}$ Department

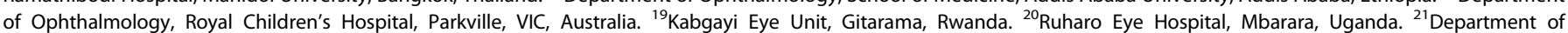
Ophthalmology, Xinhua Hospital, Shanghai Jiao Tong University School of Medicine, Shanghai, China. ${ }^{22}$ Ophthalmology Department, Great Ormond Street Children's Hospital, London, UK. A full list of members and their affiliations appears in the Supplementary Information. ${ }^{凶}$ email: didi@didifabian.com
} 
Table 1. The sex ratio among 4351 new retinoblastoma patients in 2017, and corresponding weighted sex ratio at birth.

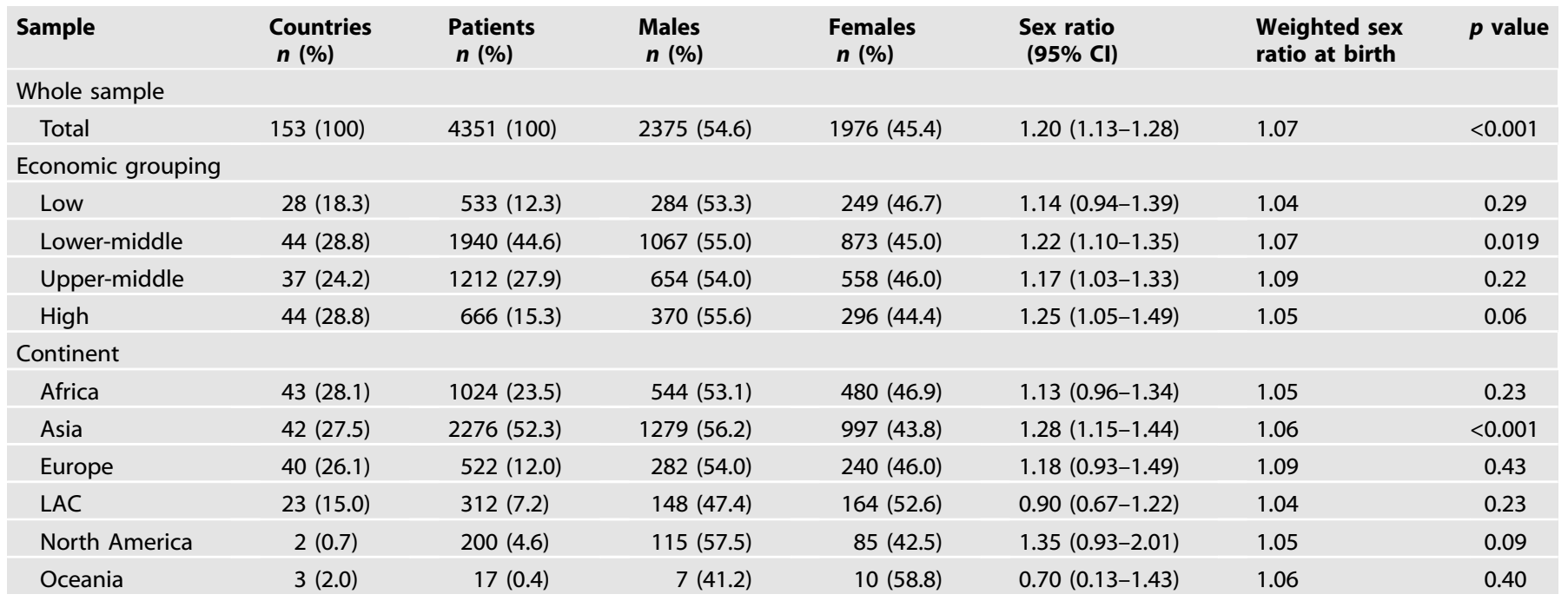

Cl Confidence interval, LAC Latin America and the Caribbean.

retinoblastoma registries [15], and which showed no difference in the male-to-female ratio, included data from several countries (19 European countries), whereas all other studies were from a single country.

In a previous report from our group [16], we presented the stage of retinoblastoma at time of diagnosis in a large sample of retinoblastoma patients from over 150 countries. In the present study, we aimed to investigate the retinoblastoma sex ratio in the same sample of patients. Our null hypothesis was that there is no sex difference between cases of retinoblastoma in the population at risk for retinoblastoma (i.e., children up to 5 years of age).

\section{METHODS}

Inclusion and exclusion criteria, patient enrollment and data collection have previously been described in detail [16]. Briefly, we conducted a 1-year observational cross-sectional analysis, including consecutive treatment-naive retinoblastoma patients who presented from January 1, 2017 to December 31,2017 to participating retinoblastoma treatment centers $(n=278)$. Data collected included patient country of residence, sex, age at presentation to the retinoblastoma center, laterality at the time of diagnosis, family history of retinoblastoma, and staging according to the 8th edition of the American Joint Committee on Cancer clinical Tumor, Node, Metastasis, Heredity (cTNMH) scheme [17]. The study was approved by the London School of Hygiene \& Tropical Medicine institutional review board (reference no. 14574) in accordance with the tenets of the Declaration of Helsinki. Participating centers, according to local institutional and national guidelines, applied to and received ethics clearance in their countries.

\section{Statistical analysis}

All analyses were performed using $\mathrm{R}$ software [18]. The sex ratio (male/ female) at birth for each country was obtained from the World Population Prospects [19], and the data were compared to the sex ratio in the present sample. Comparisons were performed at global, country economic grouping, continent and individual country level (including countries with samples $>150$ patients); and a two-sided proportions test $\left(x^{2}\right.$ test of homogeneity, $X^{2}$ goodness of fit for one proportion, or $z$-test for countrylevel analysis) was used. For country-level analysis, the statistical power for each country was computed using G*Power 3.1 program [20]. When the analysis involved countries being grouped together, weighted averages were used for the sex ratio at birth as follows:

$\sum_{i=1}^{n}$ (no. of patients $*$ sex ratio at birth in country $\left.\# \mathrm{i}\right) / \sum_{i=1}^{n}$ no. of patients in country \#i

Further analyses were performed to test for differences between males and females in respect to the following variables: (1) age at time of diagnosis, (2) proportion of familial retinoblastoma, (3) proportion of bilateral disease, and (4) proportion of cases with advanced disease at time of diagnosis ( $\geq c T 3$ ). Student's $t$ test was used to test for differences between means of two groups in case of continuous dependent variables, and F-test for differences between the groups' variances. Welch's correction was used when differences between variances were found to be significant. $X^{2}$ test of independence was used to test for associations between two categorical variables. $P$ values and confidence intervals $(\mathrm{Cl})$ were corrected for multiple comparisons using the Benjamini-Hochberg procedure. Summary statistics are presented as mean and $95 \% \mathrm{Cl}$.

\section{RESULTS}

The study sample consists of 4351 patients with retinoblastoma diagnosed during a single year, of whom 2375 were males and 1976 females, corresponding to an overall sex ratio of $1.20[95 \% \mathrm{Cl}$ 1.13-1.28]. Over a quarter of the participating countries (44, 28.8\%) were lower-middle income, and 42 (27.5\%) were in Asia. Nearly one half of the patients, $1940(44.6 \%)$, came from lowermiddle income countries, and more than one half, 2276 (52.3\%) were from Asia (Table 1). The mean age at time of diagnosis was 27.0 months [95\% Cl 26.3-27.6], and 3968 (91.2\%) patients were less than 5 years of age. A family history of retinoblastoma was reported in 199 (4.7\%) of 4215 patients for which these data were available. Bilateral retinoblastoma at time of diagnosis was found in 1341 (30.8\%) of 4351 patients and advanced retinoblastoma (cT3 or cT4) in $2566(62.4 \%)$ of 4114 patients (Table 2).

\section{Sex ratio differences: national income level and continent level analysis}

Table 1 shows the sex ratio and the corresponding weighted sex birth ratio for the entire sample and stratified by economic grouping and continent. The calculated population-weighted global sex ratio at birth was 1.07 , significantly lower than the overall sex ratio in the present study, 1.20 (95\% Cl 1.13-1.28, $p<0.001, \chi^{2}$ test). Significant differences between the population-weighted sex ratio at birth and the ratio among patients with retinoblastoma were found in lowermiddle income countries (1.07 vs. 1.22 [95\% Cl 1.10-1.35], respectively; corrected $p=0.019, \chi^{2}$ test) and in Asia (1.06 vs. 1.28 [95\% Cl 1.15-1.44], respectively; corrected $p<0.001, X^{2}$ test).

On further subgroup analysis at national income and continent level, no significant differences in the sex ratio were found by age at retinoblastoma diagnosis, proportion with familial retinoblastoma, proportion with bilateral, and proportion with advanced disease $(\geq \mathrm{CT} 3$ ) at time of diagnosis (Table 2 ). 
Table 2. Sex differences stratified by age at diagnosis of retinoblastoma and by familial, bilateral, and advanced retinoblastoma; analysis of 4351 patients at national income and continent level.

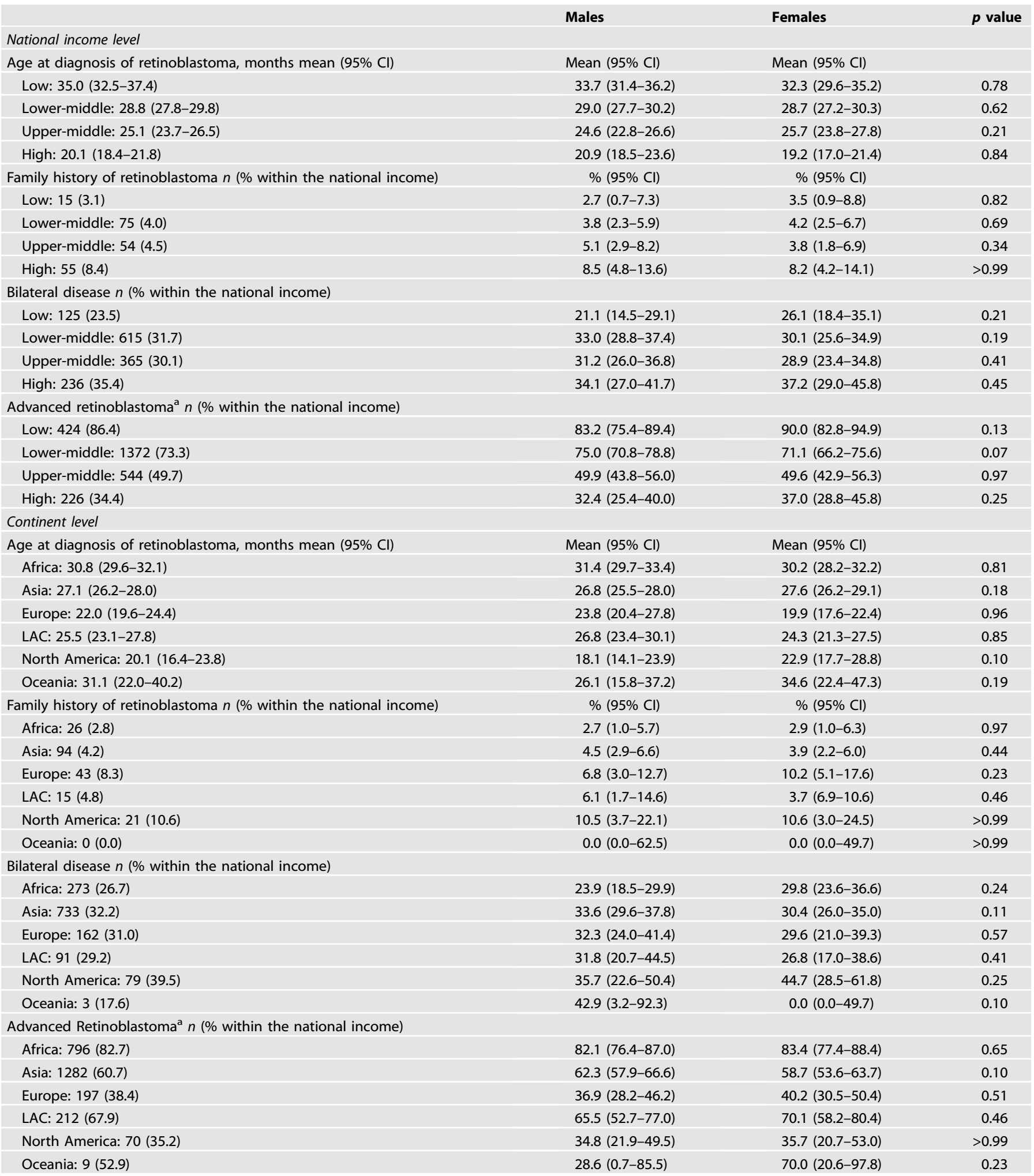

$\mathrm{Cl}$ Confidence interval, LAC Latin America and the Caribbean.

${ }^{a} \mathrm{CT} 3$ or $\mathrm{CT} 4$ of the CTNMH classification. 
Table 3. Sex ratio in 4351 patients from 153 countries diagnosed with Retinoblastoma in 2017: country-level analysis.

\begin{tabular}{|c|c|}
\hline Continent & Country: Male/Female (ratio) \\
\hline Africa & 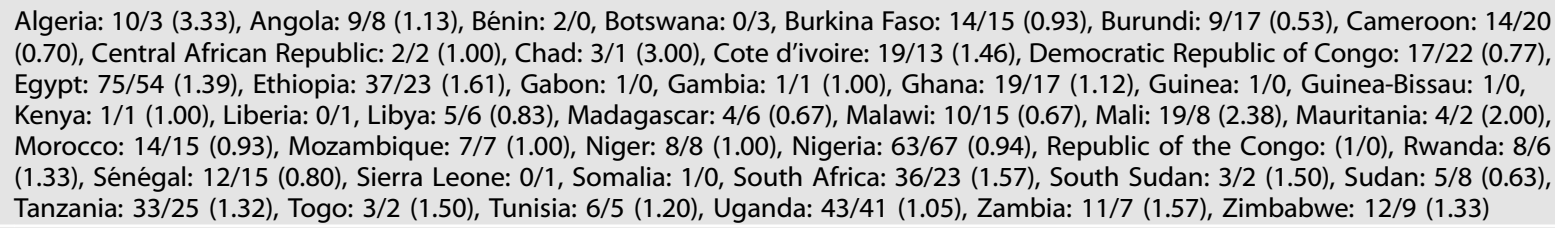 \\
\hline Asia & 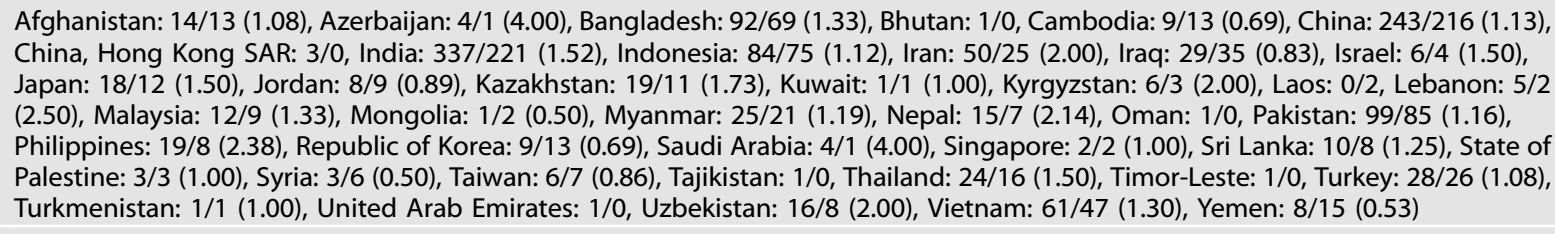 \\
\hline Europe & 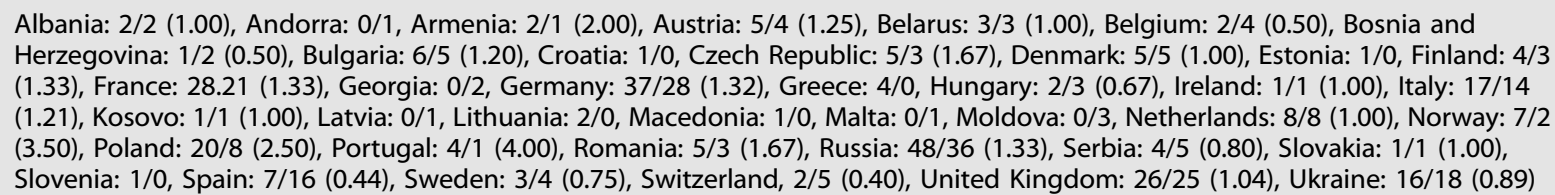 \\
\hline LAC & 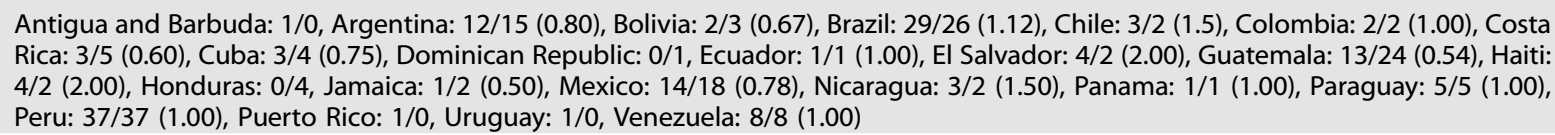 \\
\hline North America & Canada: 16/8 (2.00), United states: 99/77 (1.29) \\
\hline Oceania & Australia: 4/8 (0.50), New Zealand: $2 / 2$ (1.00), Papua New Guinea: 1/0 \\
\hline
\end{tabular}

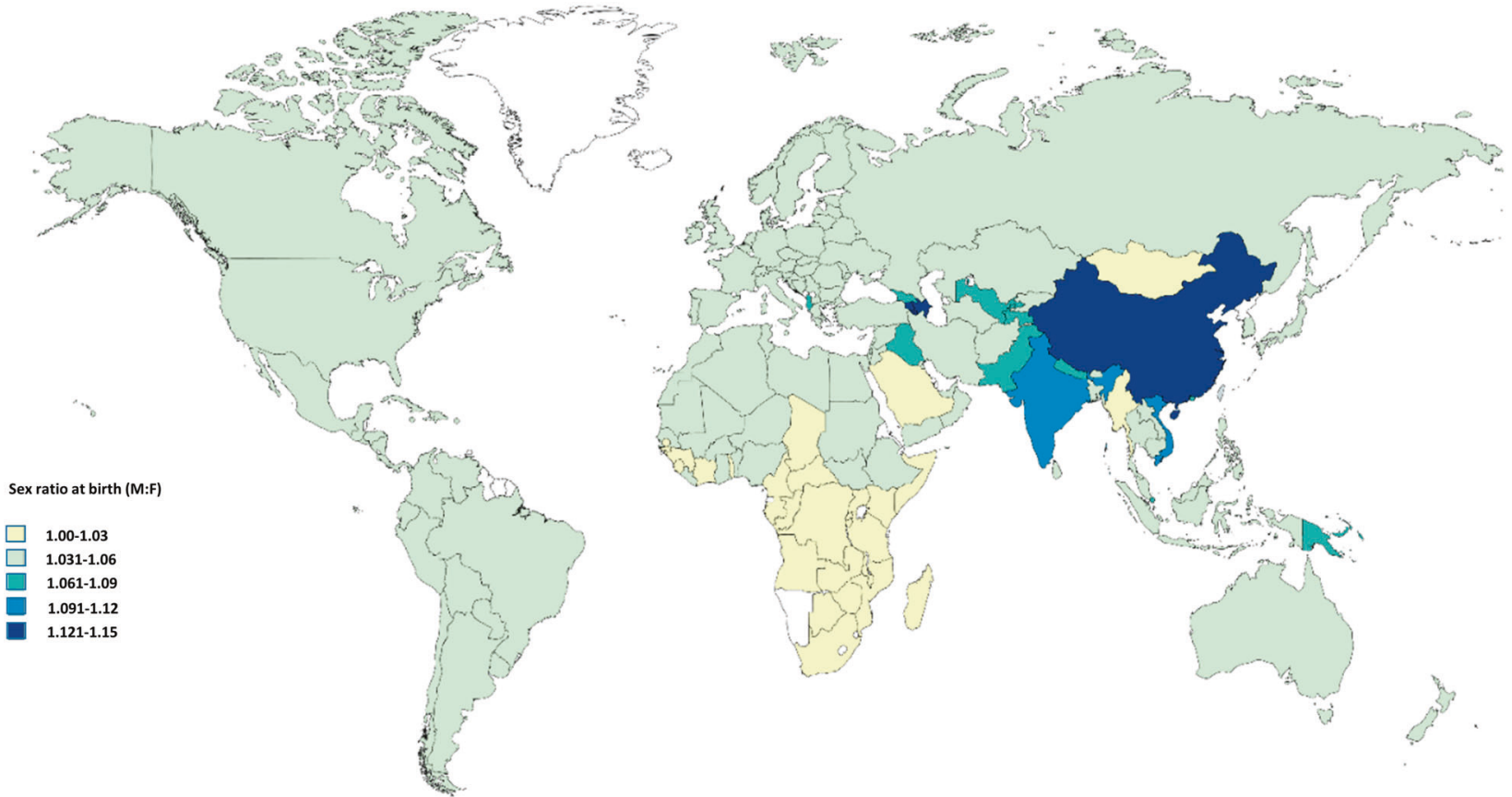

Fig. 1 Sex ratio at birth (M:F) in 153 participating countries. Retrieved from the World Population Prospects.

\section{Sex ratio differences: country-level analysis}

Table 3 shows the sex ratio in each participating country and Fig. 1 the sex ratio at birth in each country. Of the 153 countries, a sex ratio of $>1$ was found in $85(55.5 \%)$ and a ratio of $<1$ in $45(29.4 \%)$ countries, and it equaled 1 in 23 (15.0\%) countries.

Figure 2a shows the sex ratio in countries with over 150 patients as compared to the ratio at birth in these countries. A significant difference was found only in India $(n=558$; sex ratio $1.52[95 \% \mathrm{Cl}$ $1.24-1.89$ ] vs. 1.11 at birth; corrected $p=0.008, z$-test). We did not find a sex difference in any of the following in India: age at diagnosis $(p=0.24, t$ test), proportion of familial retinoblastoma $\left(p=0.52, x^{2}\right.$ test), proportion of bilateral disease $\left(p=0.10, \chi^{2}\right.$ test), and proportion of advanced disease ( $>$ CT3) at time of diagnosis $\left(p=0.81, x^{2}\right.$ test). 
a

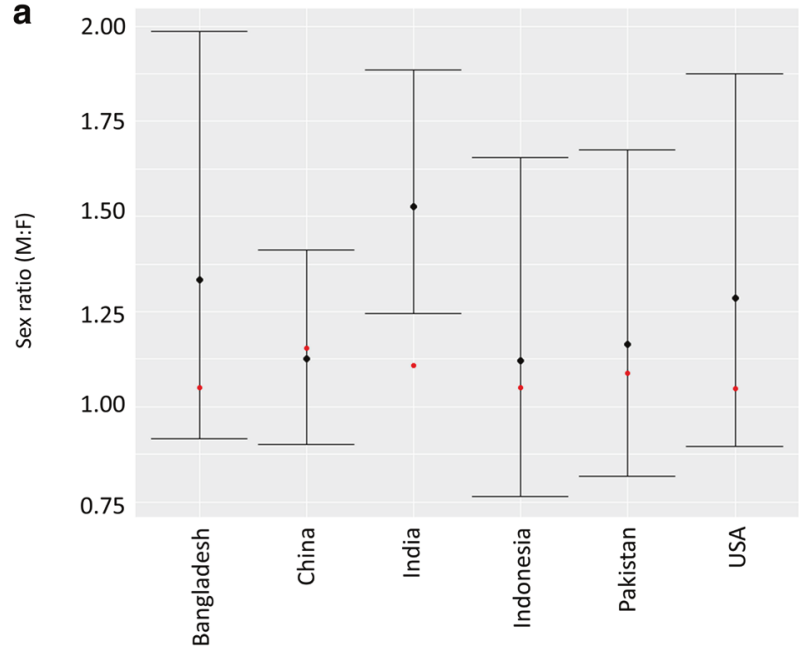

b

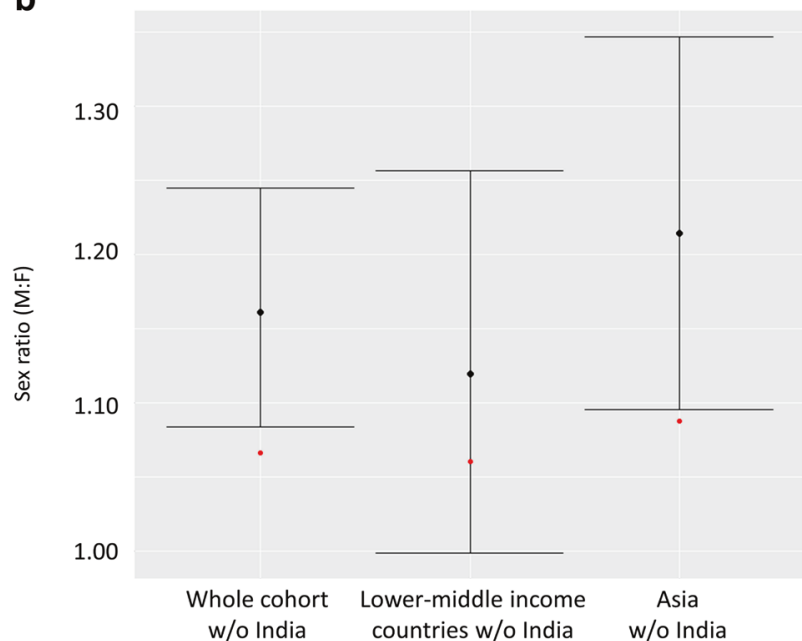

Fig. 2 Sex ratio in the sample and sex ration at birth. a Sex ratio in countries with samples of over 150 patients and corresponding sex ratio at birth. Black dot-sex ratio in each country, bars-95\% confidence interval of the sex ratio, and red dot-sex ratio at birth. Significant differences were found only in India (corrected $p=$ 0.008). b Sex ratio on whole sample analysis, lower-middle income countries and Asia, with data from India excluded, and corresponding sex ratio at birth. Black dot-sex ratio in each region/continent, bars-95\% confidence interval of the sex ratio, and red dot-sex ratio at birth. On two-sided proportions test, differences were found to be significant only on whole sample analysis $(p=0.025)$ and analysis of Asian countries (corrected $p=0.036$ ).

The sex ratios in Bangladesh $(n=161)$, China $(n=459)$, Indonesia $(n=159)$, Pakistan $(n=184)$, and the United States $(n=176)$ were $1.33,1.13,1.12,1.16$, and 1.29, respectively. Statistical power, given $a=0.05$, was $\leq 0.29$ for all these comparisons that did not show a difference from the corresponding sex ratio at birth in each country ( $p \geq 0.15, z$-test).

\section{Sex ratio differences: sensitivity analysis}

On sensitivity analysis, when excluding data from India (Fig. 2b), a significant difference in the observed sex ratio as compared to the corresponding population-weighted ratio at birth remained for the remaining cohort $\left(x^{2}=6.925\right.$, corrected $\left.p=0.025\right)$ and for Asia as a continent $\left(x^{2}=5.084\right.$, corrected $\left.p=0.036\right)$.

When analysing lower-middle income countries after excluding India, no significant differences were found $\left(x^{2}=0.972, p=0.32\right)$ and, similarly, none were found when analysing the remaining cohort with Asia excluded $\left(x^{2}=2.205, p=0.14\right)$.

\section{DISCUSSION}

Analysis of the entire sample suggests that the null hypothesis of no sex ratio difference between patients with retinoblastoma diagnosed in 2017 and the population at risk should be discarded and that an alternative hypothesis of a male preponderance corresponding to a sex ratio of 1.20 should be favored. Subgroup analysis, corrected for multiple comparisons, suggests that the observed difference in the sex ratio mainly derives from Asia and, especially, from India, both of which were responsible for a large part of the sample (over $1 / 8$ of the patients were from India and over $1 / 2$ from Asia). In the remaining regions, a significant difference was not observed, suggesting either that the null hypothesis is true or that, at least for some countries, the sample size was insufficient to detect a true difference as significant.

One possible explanation for the observed difference in the sex ratio between Asia and the other continents could be genderbased discrimination. Gender differences in health and mortality in India and other South Asian countries have been reported [2123]. The "Million Death Study" documented substantial differences between sexes in India [24]. According to this report, girls aged 5 years or less had significantly higher mortality rates from infectious causes than boys. In another report, female mortality in the age group under 5 years exceeded male mortality by $25 \%$ in nearly all states of India (corresponding to about 74,000 excess deaths in girls) [25]. It has been stated that inequities in access to care were a more plausible explanation than biological factors for the recorded differences between sexes in these studies.

Gender-based discrimination by means of neglect of girls in preventive and curative healthcare has also been reported in Nepal [26], Bangladesh [27, 28], Pakistan [29], and China [30]. In our study, we did not observe significant differences in sex ratio in these countries, although the relatively small samples in each of them may have precluded identification of such a difference.

A systematic review of gender inequalities in access to surgery for bilateral cataract among children in low-income countries found that girls had significantly lower access in some regions than boys, especially in the Asia region [31]. In retinoblastoma, which is a fatal cancer if not treated, but curable if diagnosed and treated early, gender-based discrimination has been reported only anecdotally; a retrospective analysis of 602 patients with retinoblastoma who presented to a center in northern India from 2000 to 2014 reported a sex ratio of 1.56 [32]. The authors concluded that "a male preponderance in childhood cancers in Indian studies is typical and often attributed to a bias for preferential care of male children in the society". Interestingly, in their study the authors also found that treatment noncompliance was more common for females than males ( $64 \%$ vs. $36 \% ; p=0.02)$, supporting the same conclusion. In a study investigating the clinical presentation and outcome of 600 children diagnosed with retinoblastoma in New Delhi in north India from 2009 to 2013, the sex ratio was 1.58 [33]. The authors suggested that the excess of male patients was due to genderbased referral bias. It should be noted, however, that a sex ratio of 1.5 or more (before correcting for sex ratio at birth) has not been reported in all large-cohort studies on retinoblastoma in India. Moreover, a study on presentation and outcome of 1,457 patients diagnosed with retinoblastoma in Hyderabad in south India from 2000 to 2015 reported a sex ratio of 1.26 [34]. It has been suggested that differences between districts and regions in India may have a role in this context [24].

Given our findings and the previous literature on gender-based discrimination, our conclusion is that the observed sex ratio in the present study is not biological but gender-related, due to environmental and societal factors (i.e., social, political and/or cultural) [35]. 
In our study, girls and boys presented at the same age and were diagnosed with the same disease stage, including in Asia and India. These findings support the hypothesis that there is no biological, sex-related difference in retinoblastoma. With respect to gender-based discrimination, a possible explanation for our findings is that once parents/guardians noticed an ocular abnormality, the main decision was whether or not to access services, with no delay in accessing services by parents who decided to do so. These, however, are only assumptions that necessitate further investigation.

This study has several limitations. We did not take into account sex differences in infant deaths. However, even in regions with a relatively high infant mortality rate (e.g., about $8 \%$ of all live births in south Asia) [36], the impact on our analysis would be small. If anything, assuming that retinoblastoma affects males and females equally, and because globally more boys die than girls [19], it is likely that our findings are an underestimation of the real difference in sex ratio. Another limitation is the study period of 1 year, which yielded just under 4,500 patients. As evidenced in the post-hoc statistical power calculation, the sample size was insufficient when broken down to country level. That said, this study, to the best of our knowledge, is the largest study of retinoblastoma in terms of sample size, and the most geographically comprehensive.

In summary, we aimed to investigate whether there are sex ratio differences in retinoblastoma in a large global sample and found no consistent support for this assumption, data which are useful for epidemiologists, geneticists and other medical practitioners in the field. However, we found suggestive evidence that gender discrimination in favor of boys may exist for patients with retinoblastoma in certain Asian countries, particularly in India. These findings, which add to existing literature on gender-based discrimination in child health in parts of South Asia, can be used by researchers and policy makers to address gender-based inequities.

\section{SUMMARY}

What was known before

- It is not clear whether there are sex differences in retinoblastoma, the most common intraocular malignancy of childhood.

- The literature on retinoblastoma disease consists mainly of small, single-centre case series.

- In the vast majority of studies, the question of sex ratio associated with retinoblastoma was not addressed, and in most, the retinoblastoma sex ratio was not compared to the sex ratio at birth.

- In the few studies in which retinoblastoma sex ratio was investigated, results were mixed, showing male, female or no sex predilection at all.

What this study adds

- This study reports the largest sample of retinoblastoma patients to date, including over half of the estimated annual global incidence of cases. It therefore allows for the first time to answer the sex question.

- Findings of the present analysis suggest that there is no sex predilection associated with retinoblastoma.

- However, they suggest that differences do exist in specific countries, mainly in in Asia, India in specific, and are probably related to gender discrimination in this region.

\section{DATA AVAILABILITY}

Raw data are available at https://zenodo.org/record/3727687\#.X1x_q-gzblU.

\section{REFERENCES}

1. Pui $\mathrm{CH}$, Boyett JM, Relling MV, Harrison PL, Rivera GK, Behm FG, et al. Sex differences in prognosis for children with acute lymphoblastic leukemia. J Clin Oncol. 1999;17:818-24. http://www.ncbi.nlm.nih.gov/pubmed/10071272. Accessed 26 May 2019.

2. Özdemir BC, Csajka C, Dotto G-P, Wagner AD. Sex differences in efficacy and toxicity of systemic treatments: an undervalued issue in the era of precision oncology. J Clin Oncol. 2018;36:2680-3 http://ascopubs.org/doi/10.1200/ JCO.2018.78.3290Accessed 26 May 2019.

3. Kivelä $T$. The epidemiological challenge of the most frequent eye cancer: retinoblastoma, an issue of birth and death. Br J Ophthalmol. 2009;93:1129-31.

4. Sparkes RS, Sparkes MC, Wilson MG, Towner JW, Benedict W, Murphree AL, et al. Regional assignment of genes for human esterase $D$ and retinoblastoma to chromosome band 13q14. Science. 1980;208:1042-4. http://www.ncbi.nlm.nih. gov/pubmed/7375916. Accessed 18 May 2019.

5. Tsutsumi M, Hattori H, Akita N, Maeda N, Kubota T, Horibe K, et al. A female patient with retinoblastoma and severe intellectual disability carrying an $\mathrm{X} ; 13$ balanced translocation without rearrangement in the RB1 gene: a case report. BMC Med Genom. 2019;12:182. http://www.ncbi.nlm.nih.gov/pubmed/31806026. Accessed 25 Dec 2019.

6. Cross HE, Hansen RC, Morrow G, Davis JR. Retinoblastoma in a patient with a 13qXp translocation. Am. J Ophthalmol. 1977;84:548-54. http://www.ncbi.nlm. nih.gov/pubmed/910860. Accessed 25 Dec 2019.

7. Stambolian D, Sellinger B, Derrington D, Sargent R, Emanuel BS. Cytogenetic and molecular investigation of a balanced $\mathrm{Xq} 13 \mathrm{q}$ translocation in a patient with retinoblastoma. Am J Med Genet. 1992;42:771-6. http://www.ncbi.nlm.nih.gov/ pubmed/1554012. Accessed 25 Dec 2019.

8. Orzack SH, Stubblefield JW, Akmaev VR, Colls $P$, Munné S, Scholl T, et al. The human sex ratio from conception to birth. Proc Natl Acad Sci. 2015;112:E2102-11. http://www.ncbi.nlm.nih.gov/pubmed/25825766 Accessed 27 May 2019.

9. Naumova A, Sapienza C. The genetics of retinoblastoma, revisited. Am J Hum Genet. 1994;54:264-73. http://www.ncbi.nlm.nih.gov/pubmed/8304343 Accessed 27 May 2019.

10. Wong JR, Tucker MA, Kleinerman RA, Devesa SS. Retinoblastoma incidence patterns in the US Surveillance, Epidemiology, and End Results program. JAMA Ophthalmol. 2014;132:478-83.http://archopht.jamanetwork.com/article.aspx? doi=10.1001/jamaophthalmol.2013.8001 Accessed 16 Apr 2019.

11. Li S-Y, Chen SC-C, Tsai C-F, Sheu S-M, Yeh J-J, Tsai C-B. Incidence and survival of retinoblastoma in Taiwan: a nationwide population-based study $1998-2011$. Br J Ophthalmol. 2016;100:839-42. http://bjo.bmj.com/lookup/doi/10.1136/ bjophthalmol-2015-307211 Accessed 27 May 2019.

12. Gurney JG, Severson RK, Davis S, Robison LL. Incidence of cancer in children in the United States. Sex-, race-, and 1-year age-specific rates by histologic type. Cancer. 1995;75:2186-95. http://www.ncbi.nlm.nih.gov/pubmed/7697611 Accessed 16 Apr 2019.

13. Tamboli A, Podgor MJ, Horm JW. The incidence of retinoblastoma in the United States: 1974 through 1985. Arch Ophthalmol. 1990;108:128-32. http://www.ncbi. nlm.nih.gov/pubmed/2288550 Accessed 16 Apr 2019.

14. Moll AC, Kuik DJ, Bouter LM, Den Otter W, Bezemer PD, Koten JW, et al. Incidence and survival of retinoblastoma in The Netherlands: a register based study 18621995. Br J Ophthalmol. 1997;81:559-62. Accessed 16 Apr 2019http://www.ncbi. nlm.nih.gov/pubmed/9290369.

15. MacCarthy A, Draper GJ, Steliarova-Foucher E, Kingston JE, Petrovich SV, Budanov O, et al. Retinoblastoma incidence and survival in European children (1978-1997). Report from the Automated Childhood Cancer Information System project. Eur J Cancer. 2006;42:2092-102. https://linkinghub.elsevier.com/retrieve/pii/S095980490600476X. Accessed 27 May 2019.

16. Global Retinoblastoma Study Group. Global retinoblastoma presentation and analysis by national income level. JAMA Oncol. 2020;6:1-12. http://www.ncbi.nlm. nih.gov/pubmed/32105305. Accessed 1 Mar 2020.

17. Mallipatna AC, Gallie BL, Chévez-Barrios $P$, et al. Retinoblastoma. In: Amin MB, Edge SB, Greene FL, et al., editors. AJCC Cancer Staging Manual. 8th ed. New York: Springer; 2017.

18. R Core Team. R: a language and environment for statistical computing. Vienna, Austria: R Foundation for Statistical Computing; 2016. https://www.r-project.org/.

19. United Nations, Department of Economic and Social Affairs PD. World Population Prospects: The 2017 Revision, Volume I: Comprehensive Tables (ST/ESA/SER.A/399). 2017.

20. Erdfelder E, FAul F, Buchner A, Lang AG. Statistical power analyses using G*Power 3.1: tests for correlation and regression analyses. Behav Res Methods. 
2009;41:1149-60. http://www.springerlink.com/index/10.3758/BRM.41.4.1149. Accessed 18 May 2019.

21. Jha $P$, Kumar R, Vasa $P$, Dhingra N, Thiruchelvam D, Moineddin R. Low female [corrected]-to-male [corrected] sex ratio of children born in India: national survey of 1.1 million households. Lancet. 2006;367:211-8. https://linkinghub.elsevier. com/retrieve/pii/S0140673606679300. Accessed 29 May 2019.

22. Corsi DJ, Bassani DG, Kumar R, Awasthi S, Jotkar R, Kaur N, et al. Gender inequity and age-appropriate immunization coverage in India from 1992 to 2006. BMC Int Health Hum Rights. 2009;9 SUPPL.1:S3. https://bmcinthealthhumrights.biomedcentral.com/ articles/10.1186/1472-698X-9-S1-S3. Accessed 28 May 2019.

23. Khera R, Jain S, Lodha R, Ramakrishnan S. Gender bias in child care and child health: global patterns. Arch Dis Child. 2014;99:369-74. http://www.ncbi.nlm.nih. gov/pubmed/24344176. Accessed 29 May 2019.

24. Million Death Study Collaborators, Bassani DG, Kumar R, Awasthi S, Morris SK, Paul VK, et al. Causes of neonatal and child mortality in India: a nationally representative mortality survey. Lancet. 2010;376:1853-60. http://www.ncbi.nlm. nih.gov/pubmed/21075444. Accessed 28 May 2019.

25. Ram U, Jha P, Ram F, Kumar K, Awasthi S, Shet A, et al. Neonatal, 1-59 month, and under-5 mortality in 597 Indian districts, 2001 to 2012: estimates from national demographic and mortality surveys. Lancet Glob Heal. 2013;1:e219-26. https://linkinghub.elsevier.com/retrieve/pii/S2214109X13700731. Accessed 28 May 2019.

26. Pokhrel S, Snow R, Dong H, Hidayat B, Flessa S, Sauerborn R. Gender role and child health care utilization in Nepal. Health Policy. 2005;74:100-9. http://www. ncbi.nlm.nih.gov/pubmed/16098416. Accessed 29 May 2019.

27. Dancer D, Rammohan A, Smith MD. Infant mortality and child nutrition in Bangladesh. Health Econ. 2008;17:1015-35. Accessed 29 May 2019. http://doi.wiley. com/10.1002/hec.1379

28. Mitra AK, Rahman MM, Fuchs GJ. Risk factors and gender differentials for death among children hospitalized with diarrhoea in Bangladesh. J Health Popu Nutr. 2000;18:151-6. http://www.ncbi.nlm.nih.gov/pubmed/11262768. Accessed 29 May 2019.

29. Nuruddin R, Hadden WC, Petersen MR, Lim MK. Does child gender determine household decision for health care in rural Thatta, Pakistan? J Public Health. 2009;31:fx1-97. Accessed 29 May 2019. https://academic.oup.com/jpubhealth/ article-lookup/doi/10.1093/pubmed/fdp038

30. Attane I. The determinants of discrimination against daughters in China: evidence from a provincial-level analysis. Popul Stud. 2009;63:87-102. Accessed 29 May 2019. http://www.tandfonline.com/doi/abs/10.1080/00324720802535023

31. Gilbert CE, Lepvrier-Chomette N. Gender inequalities in surgery for bilateral cataract among children in low-income countries a systematic review. Ophthalmology. 2016;123:1245-51. https://linkinghub.elsevier.com/retrieve/pii/S0161642016001548. Accessed 14 June 2019.

32. Bhargav A, Singh U, Trehan A, Zadeng Z, Bansal D. Female sex, bilateral disease, age below 3 years, and apprehension for enucleation contribute to treatment abandonment in retinoblastoma. J Pediatr Hematol Oncol. 2017;39:e249-53. http://www.ncbi.nlm.nih.gov/pubmed/28538507. Accessed 27 May 2019.

33. Chawla B, Hasan F, Azad R, Seth R, Upadhyay AD, Pathy S, et al. Clinical presentation and survival of retinoblastoma in Indian children. $\mathrm{Br} J$ Ophthalmol. 2016;100:172-8. http://www.ncbi.nlm.nih.gov/pubmed/26061162. Accessed 8 Apr 2019.

34. Kaliki S, Patel A, Iram S, Ramappa G, Mohamed A, Palkonda VAR. RETINOBLASTOMA IN INDIA: Clinical Presentation and Outcome in 1,457 Patients (2,074 Eyes). Retina. 2019;39:379-91. http://insights.ovid.com/crossref?an $=00006982$ 201902000-00020. Accessed 16 Apr 2019.

35. Institute of Medicine. Women's health research: progress, pitfalls, and promise. Washington, DC: The National Academies Press; 2010.

36. World Health Organization. The World Health Report 2005: make every mother and child count. Geneva, Switzerland: World Health Organization; 2005.

\section{ACKNOWLEDGEMENTS}

See Appendix for the full list of collaborators of the Global Retinoblastoma Study Group.

\section{AUTHOR CONTRIBUTIONS}

Conception and design: IDF, AF, and RB. Collection and assembly of data: All authors. Data analysis and interpretation: IDF, VK, AWS, AF, SK, TTK, FLM, and MAD. Statistical analysis: ASS and TTK. Paper drafting: IDF, VK, AWS, SB, AF, DSAP, JLB, NC, GLC, LH, SK, TTK, SLF, FLM, MAD, DR, STS, SES, TT, KW, XJ, NJA, CB, MB, MZ, and RB. Paper drafting: IDF, AF, TTK, and RB. Critical revision of the paper for important intellectual content: All authors. Final approval of paper: All authors. Accountable for all aspects of the work: All authors.

\section{FUNDING}

MJB is supported by grants from the Wellcome Trust (207472/Z/17/Z).

\section{COMPETING INTERESTS}

The authors declare no competing interests.

\section{ETHICAL APPROVAL}

The study was approved by the London School of Hygiene \& Tropical Medicine institutional review board (reference no. 14574) in accordance with the tenets of the Declaration of Helsinki.

\section{ADDITIONAL INFORMATION}

Supplementary information The online version contains supplementary material available at https://doi.org/10.1038/s41433-021-01675-y.

Correspondence and requests for materials should be addressed to I.D.F.

Reprints and permission information is available at http://www.nature.com/ reprints

Publisher's note Springer Nature remains neutral with regard to jurisdictional claims in published maps and institutional affiliations.

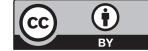

Open Access This article is licensed under a Creative Commons Attribution 4.0 International License, which permits use, sharing, adaptation, distribution and reproduction in any medium or format, as long as you give appropriate credit to the original author(s) and the source, provide a link to the Creative Commons license, and indicate if changes were made. The images or other third party material in this article are included in the article's Creative Commons license, unless indicated otherwise in a credit line to the material. If material is not included in the article's Creative Commons license and your intended use is not permitted by statutory regulation or exceeds the permitted use, you will need to obtain permission directly from the copyright holder. To view a copy of this license, visit http://creativecommons. org/licenses/by/4.0/.

(c) The Author(s) 2021 